\title{
Mikrostruktura i własności złączy naprawczych wykonanych na stopie Hastelloy $X$ przed i po eksploatacji w turbinie gazowej
}

\author{
Microstructure and properties of repair welds \\ with the use of Hastelloy $X$ alloy \\ in the delivery condition and after long term service
}

\section{Streszczenie}

Przedmiotem badań były złącza spawane ze stopu niklu umacnianego roztworowo o nazwie handlowej Hastelloy X. Proces spawania przeprowadzono metodą GTAW ( $z$ ang. Gas Tungsten Arc Welding) na materiale w stanie dostawy oraz po eksploatacji tj. pochodzącym z turbiny gazowej. W celu porównania zmian mikrostrukturalnych i własności wykonano badania za pomocą mikroskopii świetlnej, skaningowej oraz pomiary mikrotwardości. Dodatkowo przeprowadzono badania za pomocą transmisyjnej mikroskopii elektronowej (TEM) w obszarze materiału rodzimego po eksploatacji. Wykonane badania TEM były podstawą do stwierdzenia, iż temperatura eksploatacji wpłynęła jedynie na zwiększenie ilości i średnicy wydzieleń węglików typu M6C, natomiast temperatura eksploatacji leżała poza zakresem wydzielania faz wtórnych węglików typu $\mathrm{M}_{23} \mathrm{C}_{6}$ i faz topologicznie zwarcie wypełnione $\sigma$ lub $\mu$. Hastelloy $X$ w stanie przesyconym charakteryzuje się bardzo dobrą spawalności, jednakże może ona ulec obniżeniu w wyniku obecności kruchych i niskotopliwych faz powstałych w trakcie eksploatacji.

Słowa kluczowe: Hastelloy $X$; turbina gazowa; nadstopy
Abstract

The aim of the present study was to characterize repair welds performed on solid solution strengthened nickel-based superalloy also known Hastelloy $X$. The welding process was performed using GTAW. Process was carried out on materials in solid solution condition (unaged state) and after long term service in gas turbine. In order to compare microstructural changes and properties of welds light microscopy, scanning electron microscopy and microhardness measurements were performed. Additionally, transmission electron microscopy (TEM) of the base material after long term service was carried out. TEM study was the basis for the conclusion that the operating temperature had an impact on increase the amount and diameter of M6C-type carbides. Operating temperature of the turbine part was too low to contribute to the precipitation of $\mathrm{M}_{23} \mathrm{C}_{6}$ - type carbides and topologically closed packed phases $\sigma$ and $\mu$. Alloy in solid solution condition has excellent weldability but precipitation of brittle and low melting temperature constituents during service may affect the tendency to cracking.

Keywords: Hastelloy X; gas turbine; superalloys

\section{Wstęp}

Stopy niklu są wykorzystywane przy budowie energetycznych turbin gazowych, głównie na elementy pracujące w bardzo wysokich temperaturach i silnie agresywnym środowisku korozyjnym. Ekstremalnie trudne warunki eksploatacji sprawiają, że obecnie są materiałami bezkonkurencyjnymi na wysokotemperaturowe elementy turbin.

W przemyśle energetycznym i wydobywczym od ponad 50 lat stanowią ważne ogniwo w konstrukcji jednostek [1]. Spawalność stopów niklu, a więc bezpośrednio związana z tym trwałość połączeń spawanych jest silnie zależna, niekiedy nawet ograniczona przez mikrostrukturalną niestabilność. Hastelloy $X$ został zaprojektowany na elementy pracujące w temperaturze do $900{ }^{\circ} \mathrm{C}$ w związku z czym mikrostruktura ze stanu przesyconego po tysiącach godzin pracy może w znaczącym stopniu się zmienić [2]. W stanie przesyconym mikrostruktura stopu Hastelloy X składa się z osnowy y oraz pierwotnych węglików typu M6C bogatych w molibden. W swojej pracy Zhao, Larsen i Ravikumar zebrali informacje na temat zmian mikrostrukturalnych $w$ stopie Hastelloy $X$ opracowując wykres CTPi [3].

\section{Metodyka badań}

Przedmiotem badań były dwa złącza spawane wykonane ze stopu niklu o nazwie handlowej Hastelloy X. Pierwsze

mgr inż. Łukasz Rakoczy; dr hab. inż. Anna Zielińska-Lipiec, prof. AGH; dr inż. Lechosław Tuz - AGH Akademia Górniczo-Hutnicza w Krakowie.

Autor korespondencyjny/Corresponding author: Irakoczy@agh.edu.pl 
Tablica I. Skład chemiczny stopu

Table I. Chemical composition of Hastelloy X alloy

\begin{tabular}{|c|c|c|c|c|c|c|c|c|c|c|c|c|}
\hline Pierwiastek & Cr & Fe & Mo & Co & W & C & Mn & Si & Nb & Al & B & Ni \\
\hline$\%$ wt. & 20,38 & 14,8 & 9,22 & 1,39 & 0,76 & 0,05 & 0,42 & 0,5 & 0,36 & 0,12 & 0,0004 & reszta \\
\hline
\end{tabular}

złącze wykonano na materiale w stanie przesyconym, natomiast drugie na materiale po eksploatacji pochodzącym z turbiny gazowej. Złącza zostały wykonane metodą GTAW przy użyciu materiału dodatkowego Hast-X (ERNICrMo-2) o takim samym składzie chemicznym jak materiał rodzimy [4]. Skład chemiczny stopu podano w tabeli I. Trawienie złączy do badań za pomocą mikroskopii świetlnej i skaningowej przeprowadzono w odczynniku Kalling'a. Badania wykonano odpowiednio na urządzeniach Leica DM400 i FEI Nova NanoSEM 450. Przygotowanie cienkich folii poprzedziło szlifowanie mechaniczne do grubości $55 \mu \mathrm{m}$, dimplowanie do $20 \mu \mathrm{m}$ oraz ścienianie jonowe. Obserwacje przeprowadzono na mikroskopie JEOL JEM-2010 ARP. Pomiary mikrotwardości HV0,3 wykonano przy pomocy urządzenia Zwick/Roell.

\section{Wyniki badań}

\section{Charakterystyka materiałów rodzimych}

Procesowi spawania poddano materiał $\mathrm{w}$ stanie przesyconym (rys. 1a) oraz materiał po eksploatacji w turbinie gazowej (rys.1b). W wyniku trawienia ujawniono duże równoosiowe ziarna osnowy z nielicznymi bliźniakami wyżarzania. Obecność węglików $\mathrm{M}_{6} \mathrm{C}$ na granicach ziaren i w ich objętości potwierdzono za pomocą mikroskopii skaningowej i transmisyjnej.
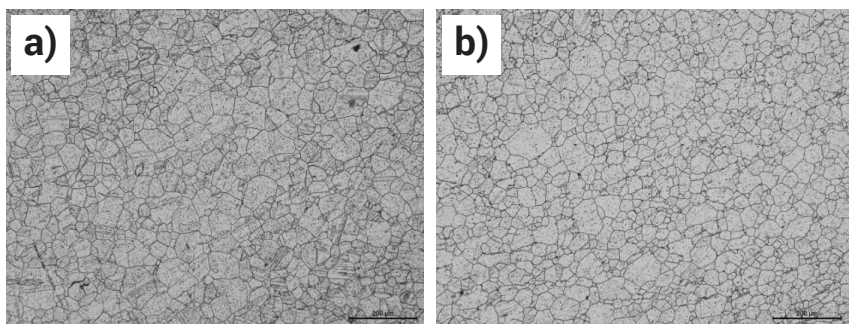

Rys. 1. Mikrostruktura materiału rodzimego: a) stan przesycony; b) po eksploatacji

Fig. 1. Microstructure of base metal: a) solid solution condition; b) after long term service

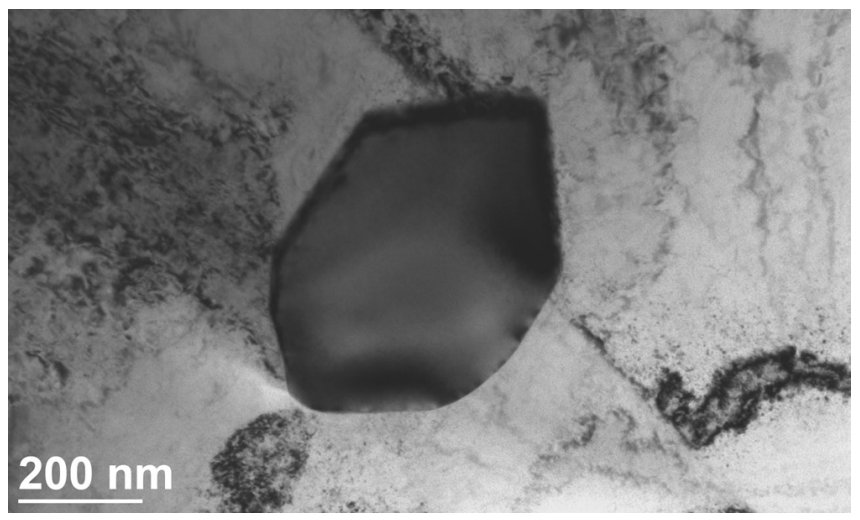

Rys. 2. Wydzielenie węglika $\mathrm{M}_{6} \mathrm{C}$ w materiale po eksploatacji

Fig. 2. Precipitation of $\mathrm{M}_{6} \mathrm{C}$-type carbide in long term serviced alloy

W stanie dostawy, a więc w stanie przesyconym, Hastelloy $X$ charakteryzuje się bardzo dobrą spawalnością, jednakże mikrostruktura podczas pracy ulega zmianie w związku z czym może mieć wpływ na skłonność materiału do pęknięć.
W celu doboru parametrów spawania istotna jest znajomość zmian mikrostrukturalnych spowodowanych eksploatacją.

Badanie cienkich folii za pomocą TEM pozwoliły ujawnić obecność pojedynczych wydzieleń wewnątrz ziaren. Przykładową morfologię wydzielenia pokazano na rysunku 2. W materiale rodzimym po eksploatacji przy pomocy transmisyjnego mikroskopu elektronowego zaobserwowano jedynie węgliki $\mathrm{M}_{6} \mathrm{C}$, co może wskazywać zgodnie $\mathrm{z}$ danymi [3] (rys. 3), że średnia temperatura pracy nie przekroczyła $500^{\circ} \mathrm{C}$. Wielkość węglików wskazuje na stosunkowo długi czas pracy. W materiale rodzimym w stanie dostawy w mikrostrukturze węgliki są drobnodyspersyjne [2] i skutecznie ograniczają ruch dyslokacji. Z kolei węgliki, których średnica przekracza $500 \mathrm{~nm}$ nie są czynnikiem umacniającym.

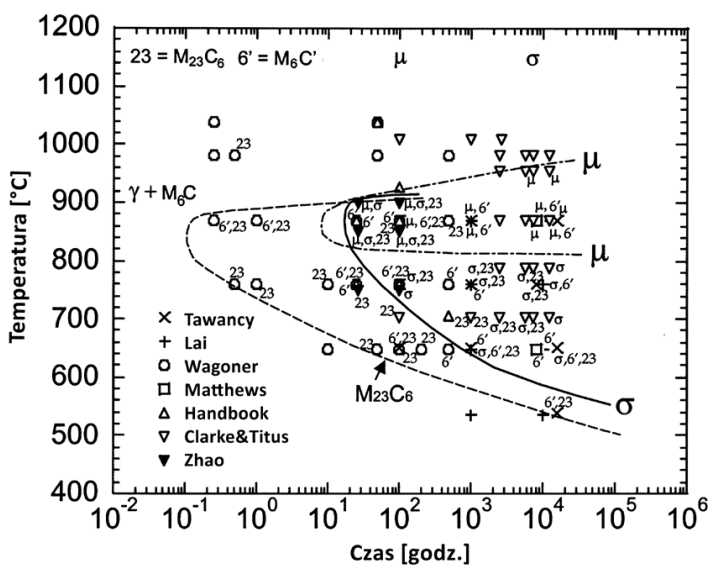

Rys. 3. Wykres CTPi dla stopu Hastelloy X [3]

Fig. 3. TTT diagram for Hastelloy $X$

\section{Mikrostruktura złączy spawanych}

Mikrostruktury złączy obejmujące spoinę, strefę wpływu ciepła i materiał rodzimy przedstawiono na rysunku 4. Podczas badań mikrostruktury nie stwierdzono obecności niezgodności spawalniczych, w związku z czym można stwierdzić, iż parametry procesu spawania zostały dobrane prawidłowo.

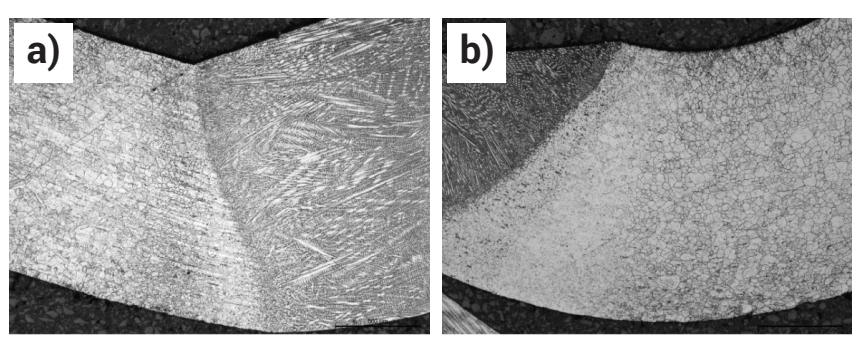

Rys. 4. Mikrostruktura złączy wykonanych na stopie w stanie: a) przesyconym; b) po eksploatacji

Fig. 4. Microstructure of repair welds conducted on Hastelloy $X$ : a) solid solution condition; b) after long term service

Zaobserwowano bardzo wąski obszar wymieszania, charakterystyczny dla złączy od którym wymagana jest wysoka odporność na korozję w podwyższonej temperaturze pracy. Spawanie przeprowadzono ze stosunkowo niską energią 
liniową w celu zminimalizowania segregacji na linii wtopienia (rysunek 4a). Znaczące różnice mikrostrukturalne ujawniono w procesie trawienia w obszarze strefy wpływu ciepła złącza wykonanego na materiale po eksploatacji (rysunek 4b). W celu uzyskania informacji o morfologii wydzieleń w strefie wpływu ciepła w pobliżu linii wtopienia wykorzystano skaningową mikroskopię elektronową. Na rysunku 5 pokazano wydzielenia na granicach ziaren.
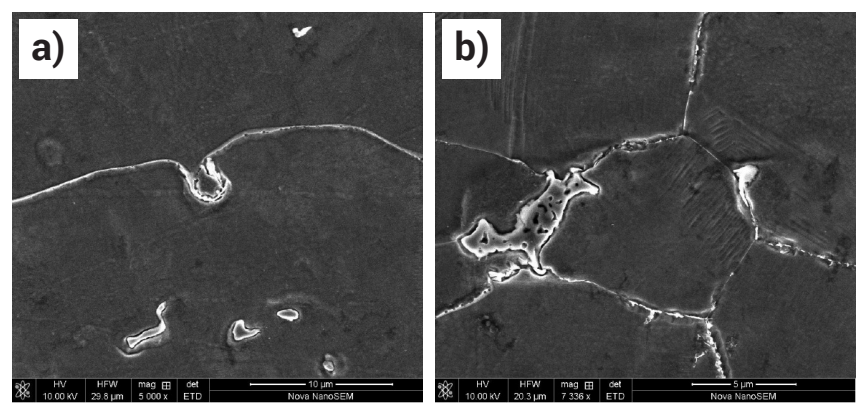

Rys. 5. Wydzielenia w strefie wpływu ciepła: a) węgliki w złączu wykonanym na stopie w stanie przesyconym; b) eutektyka w złączu wykonanym na stopie po eksploatacji

Fig. 5. Precipitation in heat affected zone; a) carbides in unaged alloy; b) eutectic in serviced alloy
Cechą charakterystyczną dla obydwu złączy jest to, że wydzielenia w strefie wpływu ciepła zostały częściowo rozpuszczone. Szybkość chłodzenia po spawaniu była na tyle wysoka, iż nie nastąpiło powtórne wydzielenie węglików. W złączu wykonanym na stopie w stanie przesyconym, granice ziaren są obsadzone węglikami (rysunek 5a). W złączu wykonanym na materiale po eksploatacji oprócz wydzieleń na granicach ziaren obserwowano tworzenie obszarów eutektycznych (rysunek 5b), co wskazuje, iż temperatura topnienia tych obszarów lokalnie uległa obniżeniu. Przy odpowiednio wysokim poziomie naprężeń może się to przyczyniać do pękania likwacyjnego [5].

\section{Pomiar mikrotwardości}

Pomiary mikrotwardości obydwu złączy wykonano w materiale rodzimym, strefie wpływu ciepła i w spoinie. W każdym z tych obszarów wykonano 3 pomiary. Wyniki zostały zestawione w tabeli II. Złącze wykonane na stopie w stanie przesyconym oznaczononumerem 1, natomiast na stopie po eksploatacji numerem 2.

Mikrotwardość stopu po eksploatacji jest wyższa o okoto $40 \mathrm{HV0,3}$ względem materiału po przesycaniu. Podobną zależność obserwuje się w strefie wpływu ciepła. Twardość w spoinie miała zbliżone wartości, ponieważ wykonano ją z użyciem tego samego materiału dodatkowego.

Tablica II. Wyniki pomiaru mikrotwardości HV0,3

Table II. Microhardness HV0,3 results

\begin{tabular}{|c|c|c|c|c|c|c|c|c|c|}
\hline $\begin{array}{c}\text { Obszar } \\
\text { pomiaru }\end{array}$ & \multicolumn{3}{|c|}{ Spoina } & \multicolumn{3}{c|}{ Strefa wpływu ciepła } & \multicolumn{4}{c|}{ Materiał rodzimy } \\
\hline $\mathbf{1}$ & 212 & 221 & 225 & 212 & 229 & 243 & 216 & 213 & 224 \\
\hline 2 & 216 & 215 & 225 & 234 & 268 & 267 & 253 & 261 & 256 \\
\hline
\end{tabular}

\section{Wnioski}

Na podstawie zrealizowanych badań stwierdzono, że parametry procesu spawania zostały dobrane prawidłowo, co pozwoliło otrzymać złącza wolne od niezgodności spawalniczych. Badany stop w stanie przesyconym, jak i po eksploatacji charakteryzuje się bardzo dobrą spawalnością. Zmiany mikrostrukturalne wywołane eksploatacją, badane za pomocą transmisyjnej mikroskopii elektronowej, potwierdzają jedynie obecność dużych węglików typu $\mathrm{M}_{6} \mathrm{C}$. Na podstawie badań Zhao [3] oszacowano, że temperatura pracy nie przekroczyła $500{ }^{\circ} \mathrm{C}$. Temperatura była zbyt niska, aby wydzieliły się kruche fazy obniżające bardzo dobrą spawalność stopu. Twardość materiału rodzimego po eksploatacji względem materiału

w stanie przesyconym jest wyższa, jednakże wartości te są w pełni akceptowalne. Strefa wpływu ciepła mimo rozpuszczenia węglików charakteryzowała się wartościami twardości zbliżonymi do materiału rodzimego, co związane jest prawdopodobnie z umocnieniem osnowy przez rozpuszczony w niej molibden.

Badania wykonano w ramach pracy statutowej 11.11.110.299. Szczególne podziękowania dla prof. dr hab. inż. Stanisława Dymka (AGH, Akademia Górniczo-Hutnicza w Krakowie) za pomoc przy wykonaniu badań transmisyjnej mikroskopii elektronowej.

\section{Literatura}

[1] M.B. Henderson, D. Arrell, Larsson, G, M. Heobel, R.: Marchant „Nickel based superalloy welding practices for industrial gas turbine applications". Science and Technology of Welding and Joining 2004; Vol. 9, No.1: 13-21.

[2] F. Najafzadegan, H. Mansori, M. Shamanian, „Investigation Of Microstructure Of The Weld Zone Of Hastelloy X Via Pulsed Nd-Yag Laser Welds". Journal Of Advanced Materials And Processing 2013; Vol.1, No. 4: 49-56.
[3] J.-C. Zhao, M. Larsen, V. Ravikumar, „Phase precipitation and time-temperature transformation diagram of Hastelloy $X^{\prime \prime}$. Materials Science and Engineering 2000; A293: 112-119

[4] http://www.hayneswire.com/weldingproducts.html

[5] J. N. Dupont, J. C. Lippold, S.D Kiser, „Welding metallurgy and weldability of nickel-base alloys", A John Wiley \& Sons, Inc.; 2009. 